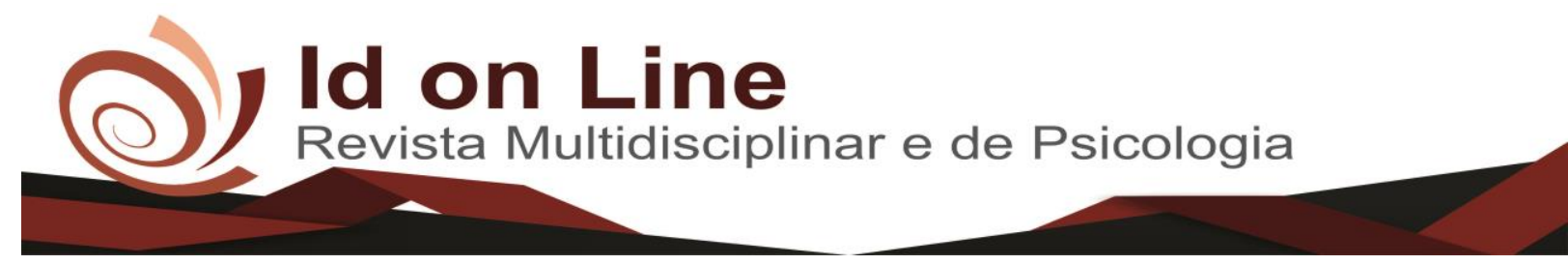

Comment

\title{
A Relevância do Planejamento Estratégico no Setor Público
}

\author{
Edilene Amorim Silva ${ }^{1}$; Fernanda Mirelle Gomes Rodrigues²; Lucinalva de Almeida Silva ${ }^{3}$
}

\begin{abstract}
Resumo: A administração pública, com perfil gerencial, estabelece seu foco no cidadão, em busca da efetividade, através do controle dos resultados e do gerenciamento. Desta forma, os usuários consistem em beneficiários e acionistas, estabelecendo relevância às suas demandas. Logo, a gestão pública obtém um delineamento competitivo, em alusão ao âmbito do setor privado, passando a utilizar terminologias incomuns no serviço público. Considerando-se a metodologia, conforme Severino (2011, p. 123), afirma, acerca da pesquisa exploratória, "é uma preparação para a pesquisa explicativa", ou seja, este tipo de pesquisa almeja revelar dados acerca de um objeto, com campo de trabalho restrito, observando-se como se dá a pronúncia deste elemento. Assim, efetuou-se uma revisão bibliográfica, realizada a partir de publicações, artigos, monografias e dissertações, alusivas à gestão estratégica no setor público. Isto posto, a presente pesquisa tem o objetivo geral de caracterizar a gestão estratégica em uma organização pública. Os objetivos específicos são apresentar os conceitos de gestão estratégica, discorrer a respeito da administração pública gerencial e demonstrar os aspectos positivos da gestão estratégica no setor público. Concluiu-se que a aplicação de técnicas de gestão estratégica, no âmbito da administração pública, é uma ação de grande relevância, visto que o tratamento do órgão público como empresa privada é capaz de promover economia de recursos públicos, além de aprimoramento da gestão, com vistas à manutenção constate da saúde financeira do setor público, satisfazendo aos cinco princípios da administração pública, quais sejam Legalidade, a Impessoalidade, a Finalidade, a Moralidade e a Publicidade.
\end{abstract}

Palavras chave: Gestão Pública. Administração Pública. Gestão Estratégica. Poder Público.

\section{Strategic Planning Relevance in the Public Sector}

Abstract: Public administration, with a managerial profile, establishes its focus on the citizen, in search of effectiveness, through control of results and management. In this way, the users consist of beneficiaries and shareholders, establishing relevance to their demands. This time, it has been that the public management obtains a competitive design, alluding to the scope of the private sector, starting to use unusual terminologies in the public service. Considering the methodology, according to Severino (2011, page 123), he says about exploratory research "it is a preparation for explanatory research", that is, this type of research aims to reveal data about an object, with field of restricted work, observing how the pronunciation of this element occurs. Thus, a bibliographic review was carried out based on publications, articles, monographs and dissertations, alluding to strategic management in the public sector. Therefore, the present research has the general objective of characterizing strategic management in a public organization. The specific objectives are to present the concepts of strategic management, to discuss about public management and to demonstrate the positive aspects of strategic management in the public sector. It was concluded that the application of strategic management techniques, within the scope of public administration, is

\footnotetext{
${ }^{1}$ Universidade Federal do Vale do São Francisco - UNIVASF. Contato: edilene.adm14@ gmail.com

2 Universidade Federal do Vale do São Francisco - UNIVASF.

${ }^{3}$ Graduada em Inglês e suas Literaturas pela Universidade Estadual de Pernambuco/UPE. Especializações em: Metodologia do Ensino de Língua Inglesa pelo Instituto Superior de Teologia Aplicada INTA Sobral-CE; Gestão e Coordenação pela UPE-Universidade Estadual de Pernambuco - Polo Afrânio-PE; Educação,Contemporaneidade e Novas Tecnologias -UNIVASF-Polo Petrolina-PE. Técnica em Serviços Públicos pelo Instituto Federal de Educação, Ciência e Tecnologia do Sertão Pernambucano-Centro de Referência de Afrânio-PE. Professora efetiva das Escolas Municipais:Clementino Coelho,(Afrânio/PE) / Laudelino Freire Mororó, (Santa Filomena/PE). Tutoria Presencial em Bacharelado em Administração Pública (Graduação/Bacharelado) Polo Afrânio-PE UFRPE/ EAD - Nível Superior/Polo Afrânio; Tutoria presencial em Gestão Pública(especialização) Polo Afrânio-PE/UNIVASF.
} 
an action of great relevance, since the treatment of the public agency as a private company is able to promote savings of public resources, besides improvement of the management, with a view to the constant maintenance of the financial health of the public sector, satisfying the five principles of public administration, namely, Legality, Impersonality, Purpose, Morality and Publicity.

Keywords: Public Management. Public administration. Strategic management. Public Power.

\section{Introdução}

$\mathrm{Na}$ atualidade, diversas modificações ocorreram e ocorrem nas organizações públicas, visando-se a intensificação da profissionalização e o aumento da eficiência e da efetividade. Desta forma, caracteriza-se a administração pública como definidora de suas ações com vistas à satisfazer as demandas dos cidadãos.

A administração pública, com perfil gerencial, estabelece seu foco no cidadão, em busca a efetividade, através do controle dos resultados e do gerenciamento. Desta forma, os usuários consistem em beneficiários e acionistas, estabelecendo relevância às suas demandas. Com isso a gestão pública obtém um delineamento competitivo, em alusão ao âmbito do setor privado, passando a utilizar terminologias incomuns no serviço público.

Considerando-se tais termos, a transparência é destacada, tendo em vista que trata-se não só de um estabelecimento em ininterrupto crescimento na sociedade, mas consiste em um princípio de ordem democrática.

Complementarmente, a responsabilidade na gestão, merece destaque e trata-se de uma tendência nas gestões privada e pública. Recentemente, o vocábulo "accountability" vem sendo utilizado com frequência, para caracterizar a referida ação do gestor, de forma que tal termo não é responsável pela apresentação correlata em uma palavra única, sendo possível sua acepção tal qual a determinação de prestação de contas dos resultados obtidos, em relação às responsabilidades decorrentes da delegação de poder.

Considerando-se a metodologia, conforme Severino (2011, p. 123), afirma, acerca da pesquisa exploratória, “é uma preparação para a pesquisa explicativa”, ou seja, este tipo de pesquisa almeja revelar dados acerca de um objeto, com campo de trabalho restrito, observando-se como se dá a pronúncia deste elemento. 
Assim, efetuou-se uma revisão bibliográfica, realizada a partir de publicações, artigos, monografias e dissertações, alusivas à gestão estratégica no setor público.

O método de abordagem utilizado foi uma suplementação entre o quantitativo e o qualitativo, com o respaldo de Gil (2010), Richardson (2011) e Severino (2011), os quais foram os autores que inspiraram a orientação para elaboração desta pesquisa.

Isto posto, a presente pesquisa tem o objetivo geral de caracterizar a gestão estratégica em uma organização pública. Os objetivos específicos são apresentar os conceitos de gestão estratégica, discorrer a respeito da administração pública gerencial e demonstrar os aspectos positivos da gestão estratégica no setor público.

\section{Planejamento e Gestão Estratégica}

O Planejamento Estratégico visa a permissão de organizações públicas ou privadas para a implementação de escolhas, enfatizando-se os recursos e esforços a serem empregados para que se possibilite sua realização. Considerando-se o tema da presente pesquisa, determinadas escolhas encontram-se de forma prévia no conceito da Missão, que consiste na razão de ser, assegurando o foco, antecipadamente, no atendimento à sociedade.

Com vistas a promover a análise do planejamento estratégico no setor público, é necessário apresentar definições básicas a respeito do planejamento e da estratégia. $\mathrm{O}$ planejamento consiste na estruturação implementada antes de realizar-se a ação, de forma que trata-se de uma maneira de construir o que será feito e como dar-se-á a sequência de procedimentos.

É possível conceituar o planejamento como uma maneira de organização pautada pela racionalização dos meios, para que possibilite-se o alcance dos objetivos e das metas.

Trata-se o planejamento de um aspecto associado à natureza do ser humano, considerando-se que é por vias deste atributo que a humanidade identifica-se e prepara-se para vencer empecilhos que lhes são contrapostos.

No âmbito corporativo, o planejamento trata-se de uma forma delineadora de um futuro que a organização deseja, sendo, desta maneira, uma projeção desejada pela organização. É um processo avaliativo e de tomada de decisão, previamente à implementação da ação, visando-se

458 Id on Line Rev. Mult. Psic. V.12, N. 42, p. 456-469, 2018 - ISSN 1981-1179 Edição eletrônica em http://idonline.emnuvens.com.br/id 
a aumentar as chances de atingir o objetivo almejado. É, portanto, a avaliação das atitudes para alterar um cenário que acredita-se que não sofrerá alteração, caso não haja ação (OTA, 2014).

Nas organizações, o planejamento é empregado tal qual um processo racional interventivo nas condições atuais, visando-se a satisfazer uma demanda atual por uma circunstância futura, compreendendo-se que trata-se de um processo de integração de decisões, capaz de estabelecer formalidade e estratégia, com o objetivo de controlar o futuro organizacional por vias da análise racional (OTA, 2014).

Os níveis do planejamento são três: estratégico, tático e operacional; ao passo em que o planejamento em nível estratégico promove a construção de um plano de visão geral, com vistas a um desenvolvimento a longo prazo, o tático consiste na desintegração dos objetivos estratégicos, em médio prazo, ao passo que o operacional realiza atividades do dia a dia, visando a manutenção da organização no curto prazo (OTA, 2014).

A Gestão Estratégica encontra-se empregada, essencialmente, para consolidar a contribuição da gestão de pessoas e recursos no desenvolvimento organizacional, considerandose o aprimoramento da definição de que a gestão pode ser implementada de forma estratégica, a partir da qual se considera palpável a gestão enquanto estratégica, como disponibilizante de vantagens competitivas para as organizações (LACOMBE; TONELLI, 2001; ALBUQUERQUE; LEITE, 2009, 2010).

De acordo com Fischer (1998) e Lengnick-Hall et al. (2009), é necessário considerar a sustentação do respaldo da gestão para as organizações, no que concerne à habilidade da referida modalidade de gestão em produzir indivíduos qualificados, de forma otimizada.

Todavia, o ambiente organizacional encontra-se submetido à eventuais alterações e turbulências, sendo comum a imprevisibilidade nos resultados das estratégias adotadas para a satisfação dos objetivos, sendo necessário enfatizar que a prometida vantagem competitiva não implica, na totalidade das ocasiões, no necessário êxito organizacional.

A administração passou por alterações de grande vulto, o que implicou em consideráveis mudanças na gestão. A evolução da contabilidade, segundo Tinoco (2005), foi um fator contributivo para que emergisse o entendimento a respeito do valor dos indivíduos nas organizações, de forma que, no contexto em tela, brotou o conceito de valor, vinculado ao produto, que se propôs com o objetivo de associar o nível de custo dos indivíduos para as 
organizações em função de sua efetiva contribuição no aporte de valor às empresas, através da qualidade de sua atividade laboral e de sua produtividade.

A Gestão Estratégica passou a adquirir atribuições vinculadas ao comportamento dos colaboradores, sendo vislumbrada pela organização como o campo responsabilizado pela gestão do seu trabalho, tendo em vista a direta implicação da referida gestão nos resultados.

As consolidações das teorias sistêmicas e comportamentais propiciaram a intensificação do valor das relações entre os indivíduos e as organizações, havendo uma identificação da demanda por condicionamento e estímulo dos indivíduos nas organizações, determinando o envolvimento do âmbito da gestão de pessoas, no sentido de promover estratégias de projeção da transparência empresarial, sendo tal imagem transposta à integralidade dos níveis organizacionais (BOXALL; PURCELL, 2008).

Assim, a estratégia organizacional mostrou às organizações a necessidade de adotar estratégias, as quais encontrar-se-iam associadas à gestão de pessoas, com ênfase na avaliação de desempenho, desenvolvimento, carreira, treinamento e remuneração.

É necessário destacar a transmissão de estratégia da organização aos colaboradores, como uma evidente propriedade da gestão de pessoas, sendo necessário que o setor responsável pela gestão dos indivíduos disponibilize respaldo aos colaboradores e estabeleça condições para os resultados, ofertando treinamentos e elementos diversos, capazes de otimizar a eficiência dos trabalhadores.

De acordo com Mazucato (2014), atualmente, há a relação da gestão à responsabilidade social, gestão estratégica de carreira, gestão para a sucessão de profissionais, governança corporativa, internacionalização das organizações, transformações no mercado de trabalho e avaliações dos resultados organizacionais em gestão de pessoas, o que ocasionou à incorporação da função da gestão, particularidades pautadas pela complexidade.

Segundo Schikmann (2010) conceitua:

\footnotetext{
A gestão estratégica se refere a um tipo de gestão que se preocupa com os objetivos e metas da organização e com o desempenho e as formas de atuação mais adequados para concretizá-los, considerando-se o curto, o médio e o longo prazos. O foco é a definição dos resultados esperados, o planejamento e o monitoramento das ações para seu alcance (SCHIKMANN, 2010, p.18).
} 
Já no que se refere a gestão estratégica de pessoas, Schikmann inclui a definição: dos perfis profissionais e da quantidade de pessoas com tais perfis, necessários para atuar na organização. Além disso, abrange o estabelecimento de uma política que oferecerá o respaldo adequado para a sustentabilidade da gestão (SCHIKMANN, 2010, p.18).

Na opinião de Schikmann (2010), “O gestor que trata da gestão estratégica de pessoas precisa estar preparado para fazer frente ao novo desafio que se apresenta com as mudanças de escopo e de abordagem até então praticados na gestão de pessoas" (SCHIKMANN, 2010, p.20).

Atualmente, a gestão estratégica de pessoas começa a despontar como uma iniciativa mais sólida, por meio do Decreto n. 5.707, de 23 de fevereiro de 2006. Com esse decreto, começaram os trabalhos para a implantação de uma Gestão por Competências no setor público.

\section{Aspectos da Gestão Estratégica no Programa de Eficiência do Gasto}

O Programa de Eficiência do Gasto (PEG), surgiu diante do compromisso estatal de harmonizar impasses oriundos das demandas sociais e devido ao limite de recursos disponíveis, com vistas a aperfeiçoar a qualidade dos gastos públicos, através da debelação das perdas e da ininterrupta otimização da gestão de processos. Desta maneira, almeja-se aperfeiçoar a prestação de serviços à sociedade.

O desenvolvimento do aludido programa tornou perceptível o potencial de agir no fomento à permuta da práticas gestoras entre entidades públicas e órgãos, tendo em vista que tais práticas, com bons resultados, encontram-se em exercício pelo Governo Federal, de forma que o PEG impulsionou tais empreendimentos, materializando-as no Banco de Boas Práticas, no qual encontram-se indexadas as referidas práticas e as benesses oriundas de sua implementação. Nesta realidade, tal sistema objetiva respaldar o Programa de Eficiência do Gasto Público, no qual as entidades contempladas recolhem os dados demandados ao Planejamento, estabelecendo-se metas de gastos e criando-se as ações, com posterior controle.

Diversos autores reconhecem como princípios da administração: planejar, organizar, dirigir e controlar. Castro (2008) afirma que o controle representa a quarta função da administração e depende do planejamento da organização e da direção para fazer parte do 
processo administrativo. Segundo o autor, na área pública o controle interno tem como objetivo “funcionar, simultaneamente, como um mecanismo de auxílio para o administrador público e instrumento de proteção e defesa do cidadão" (CASTRO, 2008, p.62). Com efeito, percebe-se a relevância do controle interno para qualquer organização e também para os órgãos públicos.

\section{Controle Interno como Ferramenta de Gestão Estratégica}

O controle interno no setor público está previsto em diversos dispositivos legais dentre eles no art. 70 da Constituição Federal que determina:

Art. 70. A fiscalização contábil, financeira, orçamentária, operacional e patrimonial da União e das entidades da administração direta e indireta, quanto à legalidade, legitimidade, economicidade, aplicação das subvenções e renúncia de receitas, será exercida pelo Congresso Nacional, mediante controle externo, e pelo sistema de controle interno de cada poder (BRASIL, 1988, p.1).

Percebe-se a relevância que o controle interno tomou no setor público em razão de sua inserção no texto constitucional. Abumahman e Zorez (2006, p.276) destacam que devido isso "cada vez mais fica patente a necessidade de institucionalizar uma unidade que assuma a sua coordenação e avaliação, como um serviço de apoio à administração".

De acordo com Poubel de Castro (2008, p.27), "historicamente, a palavra controle sempre esteve ligada às finanças. Em francês controler significa registrar, inspecionar, examinar". A palavra é originária de contre-rôle, registro efetuado em confronto com o documento original, com a finalidade da verificação da fidedignidade dos dados. No italiano, controllo é o mesmo que registro ou exame. Consagrou-se o vocábulo na técnica comercial para indicar inspeção ou exame que se processa nos papéis ou nas operações registradas nos estabelecimentos comerciais (CASTRO, 2008).

Cruz e Glock caracterizam a definição de controle:

Qualquer atividade de verificação sistemática de um registro, exercida de forma permanente ou periódica, consubstanciado em documento ou outro meio, que expresse uma ação, uma situação, um resultado etc., com o objetivo de se verificar se existe conformidade com o padrão estabelecido, ou com o resultado esperado, ou, ainda, com o que determinam a legislação e as normas (CRUZ; GLOCK, 2006, p.20). 
Conforme Souza (2006, p.10), “o controle interno representa em uma organização o conjunto de procedimentos, métodos ou rotinas com os objetivos de proteger os ativos, produzir dados contábeis confiáveis e ajudar a administração na condução ordenada de sua gestão".

No mesmo sentido, Cavalheiros e Flores corroboram que o controle interno é:

\begin{abstract}
Orientado para realizar a auto-avaliação da administração com suas (limitações usuais), abrange preocupações de ordem gerencial (eficiência e contributividade), programática (eficácia e convergência) e administrativo-legal (conformidade) (CAVALHEIRO; FLORES, 2007, p.16).
\end{abstract}

Para Hely Lopes Meirelles (1999, p.54), “controle na Administração Pública é a faculdade de vigilância, orientação e correção que um poder, Órgão ou Autoridade exerce sobre a conduta funcional de outro".

Poubel de Castro observa que pela amplitude da definição que o controle deve ser exercido em todos os níveis e em todos os setores para ser efetivo. Tanto os cidadãos como as autoridades, chefes de família ou de empresas, eleitores ou eleitos concordam de maneira quase inânime, que é necessário controlar. No entanto, e principalmente que é preciso controlar os outros.

\title{
Controles Administrativos na gestão pública
}

Os controles administrativos são associados aos procedimentos de natureza operacional e aos objetivos de uma organização, com vistas a assegurar que as políticas internas e as missões sejam satisfeitas. Na integralidade dos âmbitos da organização, o controle faz-se presente, sendo sua atribuição primária o exercício do monitoramento, da fiscalização e do controle das atividades.

Os referidos controles disponibilizam à contabilidade as informações fidedignas, estabelecendo precisão na escrituração, reduzindo a possibilidade da ocorrência de erros e desperdícios, de maneira que tais objetivos são aplicados aos controles implementados nos sistemas financeiro e contábil. Seu empreendimento em áreas diversas visam exclusivamente o respaldo patrimonial da organização (ROSA, 2007). 
Tessele (2013) relata que os controles administrativos abarcam o plano de organização e as técnicas e procederes vinculados à eficiência operacional, norteados para as políticas de negócios das organizações e, de forma indireta, associados aos registros financeiros. Ou seja, o controle administrativo apresenta o objetivo de conduzir, com celeridade, a administração à satisfação dos objetivos planejados.

\section{Controles Contábeis na administração pública}

Os controles contábeis vinculam-se, de forma direta, ao patrimônio, às demonstrações e aos registros contábeis, de maneira que seu escopo essencial é o registro das transações, com vistas a possibilitar a contínua construção das demonstrações financeiras e a conservação do controle contábil sobre os ativos da organização.

Os controles contábeis encontram-se associados ao plano organizacional e à totalidade dos procedimentos e métodos, com destaque para os que visam à proteção patrimonial e à fidedignidade dos registros contábeis, como, por exemplo, os sistemas de autorização, aprovação e conferência, assim como a auditoria interna e a segregação de funções. É finalidade do auditor externo a emissão de suas opiniões a respeito dos demonstrativos financeiros, sendo necessário que o referido profissional aprecie os controles contábeis, considerando-se que estes encontram-se ligados às concernidas demonstrações (ALMEIDA, 2003).

Determinados procederes e registros, componentes dos controles contábeis, podem ser inseridos ou superarem os controles administrativos, cujo exemplo pode ser materializado como os registros de vendes e de custos, caracterizados por produtos, sendo possível seu emprego não apenas no controle contábil, mas, também, nos controles administrativos, com vistas a lastrear a tomada de decisão.

\section{Sistema de Controle Interno: Uma Ferramenta Estratégica}

O sistema de controle interno é aquele que executa, realiza as atividades de controle interno. Conforme Souza (2006, p.10) "é aquele que efetivamente orienta, fiscaliza e ajuda a 
gestão, é responsável diariamente por esse controle das contas públicas". Identifica-se com isso que cada setor da administração pública faz arte do sistema de controle interno.

No mesmo sentido Santos e Muraro (2006) afirma que os sistemas de controles internos são utilizados tanto na esfera pública como na privada. "Um sistema de controle interno (SCI) é utilizado tanto nas empresas privadas como em instituições públicas.

Para o Comitê de Procedimentos de Auditoria do Instituto Americano de Contadores Públicos Certificados (AICPA) um SCI é aquele que abrange o plano de organização adotado pelas empresas para verificar a precisão e fidedignidade de seus dados contábeis. Ainda, através de seus procedimentos permite a proteção do patrimônio da entidade, a busca pela eficiência operacional e o encorajamento à adesão das políticas estabelecidas pela administração superior.

\section{Controle Interno no Setor Público}

\section{Auditoria e controle interno no setor público}

No concernente à auditoria interna, faz-se necessário dar relevância ao fato de que as empresas estão cada vez mais obrigadas a tornarem seus processos com custos mais baixos, a concorrência acirrada e consequentemente, a redução de suas margens de lucros, exigem que as empresas tomem medidas para viabilizar a concorrência, reduzindo, não somente seus custos de produção mas, também seus custos de gestão e operacionais, estamos vivendo um momento em que gerir recursos com economia, eficiência e eficácia é muito importante para a sobrevivência de uma empresa. Isto acaba exigindo cada vez mais de profissionais capacitados que consigam dar conta da constante mudança da legislação e economia brasileira. Diante dessa mudança, um grande número de empresas está cada vez mais optando pelo controle interno, que graças à globalização e a tecnologia oferecerem números precisos e controles eficientes que auxiliam em uma tomada de decisão frente ao mercado, cada vez mais disputado. Os chamados controles de gestão asseguram que os planos traçados pelos gestores sejam executados como o planejado (QUEIROZ, 2012).

O controle interno tem a função de dar suporte ao trabalho de auditoria, dando tratativas aos problemas encontrados e evitando assim o grande número de não conformidades. A 
necessidade de controles mais rígidos e acompanhamento contínuo dos processos de uma empresa são constantes, principalmente pelo acirramento da competitividade no mercado e pela globalização pelo qual passamos. A necessidade crescente de ajustes e redução de custos em seus processos, sejam eles industriais, comerciais ou operacionais, faz com que as empresas passem a se utilizar de ferramentas que possam tornar viáveis que se consigam atingir seus objetivos e uma das principais maneiras de obter-se a almejada redução de custos passa pela necessidade de se usar Controles Internos mais apropriados e mais rígidos, principalmente, devido ao aumento da competitividade entre as empresas, onde os membros da alta administração através dos mecanismos de gestão podem controlar as operações realizadas pela empresa, auxiliando-os na análise das perspectivas futuras, tendências de crescimento e rentabilidade atual (QUEIROZ, 2012).

A necessidade do setor público investir em revisões periódicas e uniformes com pessoal qualificado e treinado para atuar como auditor é essencial, para que se mantenha sempre um parecer sobre sua situação financeira e se os resultados do período foram alcançados. É importante evidenciar que a responsabilidade do auditor independente não se restringe a emissão de opinião sobre as demonstrações contábeis. Ele pode ter também outras responsabilidades de comunicação e de relatórios perante os usuários, a administração, aos responsáveis pela governança ou as partes fora da entidade, a respeito dos assuntos decorrentes da auditoria (QUEIROZ, 2012).

Além de examinar as demonstrações financeiras da empresa o auditor externo pode ser solicitado pelas empresas para auditoria fiscal ou de impostos, que consiste em traduzir uma expectativa positiva de mensuração de passivos fiscais adequados e provisionados de forma lícita e menos onerosa, que auxiliará a empresa a se prevenir contra desperdício ao longo do fluxo de caixa, com saídas de recursos financeiros que poderiam trazer maiores resultados para a empresa através de investimentos e maximização dos lucros operacionais. Para que possa ser feita esta análise da situação físcal da empresa é necessário que o auditor tenha amplo conhecimento na legislação fiscal, para que se possa contemplar a universalidade e consolidação de leis e dos princípios fundamentais da contabilidade.

Pode-se definir Auditoria como uma forma bem simples de levantamento, estudo e avaliação dos procedimentos, ou também como uma revisão das demonstrações contábeis, 
registros e operações financeiras de uma entidade, a fim de que ela se enquadre às normas pertinentes e à legislação pertinente. Hoog (2007, p. 65) diz que:

\begin{abstract}
Auditoria contábil é o procedimento científico relativo à certificação dos elementos da riqueza aziendal, normalmente contabilizados nas fundações, associações, sociedades empresária e simples. Assegurando a credibilidade das informações das peças contábeis e a integridade do conjunto de bens e obrigações e da situação líquida, visa a minimização ou eliminação dos riscos fiscais, societários, ambientais, trabalhistas, previdenciários, sistêmicos ou não da ambiência (HOOG, 2007).
\end{abstract}

Em busca cada vez mais do seu lugar no mercado econômico, as empresas estão investindo em auditoria. Manter todos os registros em ordem para a certificação, e talvez um dos motivos mais importantes ligados a auditoria é, tentar evitar as fraudes que estão sendo cada vez mais comuns dentro das organizações.

\title{
Controladoria: Reflexos no Setor Públicos e Implicações Estratégicas
}

O mundo globalizado demanda um mercado pautado na competitividade, determinando, desta feita, que ocorra mais empenho por parte do empresariado, com o escopo de promover a manutenção das organizações no mercado. Considerando-se o modelo de gestão pública em vigor na atualidade, é natural a implementação de procederes administrativos do setor privado no âmbito público. Tal circunstância implicou em sensíveis alterações dos padrões de comportamento da sociedade, inclusive no âmbito técnico, trazendo à baila a necessidade da implantação de planejamento estratégico no setor público. As organizações buscam a obtenção de vantagens, no concernente à tomada de decisões, ensejando a supressão de elementos passíveis de determinarem erros, sendo necessário debelar gestores desprovidos de qualificação, visto que os aludidos profissionais podem causar danos à empresa. 


\section{Conclusões}

A Gestão Pública representa o Estado no desempenho de uma função administrativa, diga-se, e deve, assim, buscar atender aos interesses da sociedade, de forma que a prestação dos serviços deve ser feita com excelência, servindo ao cidadão de forma eficiente, pois a esfera pública deve transcender a duração da vida de homens mortais, e sem esta preocupação não há esfera pública e, por sua vez, não há história.

Desta maneira, foi possível concluir que a aplicação de técnicas de gestão estratégica, no âmbito da administração pública, é uma ação de grande relevância, visto que o tratamento do órgão público como empresa privada é capaz de promover economia de recursos públicos, além de aprimoramento da gestão, com vistas à manutenção constante da saúde financeira do setor público, satisfazendo aos cinco princípios da administração pública, quais sejam Legalidade, a Impessoalidade, a Finalidade, a Moralidade e a Publicidade.

\section{Referências}

ANGÉLICO, João. Contabilidade pública. 7ª ed.. São Paulo. Ed. Atlas, 1992

BALEEIRO, Aliomar. Uma Introdução à Ciência das Finanças. 16. ed. rev. e atualizada por Dejalma de Campos. Rio de Janeiro: Forense, 2002.

BANDEIRA DE MELlO, Celso Antônio. Curso de Direito Administrativo, $14^{\mathrm{a}}$ ed. São Paulo: Malheiros, 2001.

BARROS, Luiz Celso de. Ciência das Finanças. 4a. ed. São Paulo. Edipro. 1991

BASTOS, Celso Ribeiro. Curso de direito financeiro e de direito tributário. 4. ed. São Paulo. Ed. Saraiva, 1991

BRASIL. Lei no 8.429. Lei de Improbidade Administrativa. Brasília: Senado, 1992.

BRASIL. Lei n 8.666, de 21 de junho de 1993. Regulamenta o art. 37, XXI, da Constituição Federal. http://www.planalto.gov.br/ccivil_ 03/Leis/L8666 cons.htm. Acessado em 12 de fevereiro de 2016.

CARRIER. Catálogo Técnico. Acessado em 22 de fevereiro de 2016. Disponível em: www.carrier.com.br.

CONCEIÇÃO, Francisca Lúcia; RAMOS, Erlaine Teodoro. Impactos da Lei de Responsabilidade Fiscal sobre a contabilidade pública. Monografia. TCU. Brasília. 2006. 
COSTENARO, Renan André. Cálculos de parâmetros de desempenho de uma instalação de geração de potência a vapor com carvão pulverizado. Monografia. UFRGS. Porto Alegre. 2011.

LUDÍCIBUS, Sergio de; MARION, José Carlos. Curso de contabilidade para não contadores: para

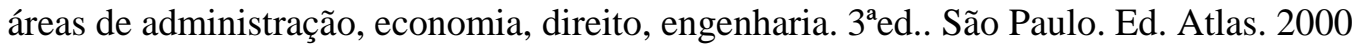

MEIRELLES, Hely Lopes. Direito Administrativo Brasileiro. 23ª ed. Malheiros. 1999.

PIRES, João Batista Fortes de Souza. Contabilidade pública. 7. ed. Brasília: Franco \& Fortes, 2002

RIO GRANDE DO NORTE. Resolução n⿳0 050. Assembleia Legislativa do Estado do Rio Grande do Norte, 2012.

ROSA JÚNIOR, Luiz Emygdio F. Manual de Direito Financeiro e Tributário. $18^{\mathrm{a}}$ ed. Rio de Janeiro: Renovar, 2005.

SANTA HELENA, Eber Zoehler. Competência parlamentar para geração e controle de despesas obrigatórios de caráter continuado e de gastos tributários. Brasília: Edições Câmara, 2009.

SILVA, Adival do Carmo. Evolução da administração pública no Brasil e tendências de novos modelos organizacionais. 2013. Disponível em: 〈http://www.ice.edu.br/f $\rangle$. Acessado em: 11 de fevereiro de 2016.

\section{Como citar este artigo (Formato ABNT):}

SILVA, Edilene Amorim; RODRIGUES, Fernanda Mirelle Gomes; SILVA, Lucinalva de Almeida. A Relevância do Planejamento Estratégico no Setor Público. Id on Line Rev.Mult. Psic., 2018, vol.12, n.42, p. 456-469. ISSN: 1981-1179.

Recebido: 22/09/2018;

Aceito: 28/09/2018 